University of Warwick institutional repository

This paper is made available online in accordance with

publisher policies. Please scroll down to view the document

itself. Please refer to the repository record for this item and our

policy information available from the repository home page for further information.

To see the final version of this paper please visit the publisher's website. Access to the published version may require a subscription.

Author(s: Richard Lampard; Kay Peggs

Article Title: Repartnering: the relevance of parenthood and gender to cohabitation and remarriage among the formerly married

Year of publication: 1999

Link to published version: http://dx.doi.org/10.1080/000713199358644

Publisher statement: None 

Repartnering: the relevance of parenthood and gender to cohabitation and remarriage among the formerly married.

[Pre copy-editing version: February 1999]

Richard Lampard and Kay Peggs

Department of Sociology, Univer sity of Warwick, COVENTRY CV4 7AL

$$
\text { and }
$$

Department of Sociology, Univer sity of Portsmouth, HANTS PO1 3AS 


\title{
Repartnering: the relevance of parenthood and gender to cohabitation and remarriage among the formerly married.
}

\begin{abstract}
$\underline{\text { Abstract }}$
This paper is an exploratory analysis of the impact of current and anticipated parenthood on cohabitation and remarriage among those formerly living in marriage-type relationships. The focus on children is embedded within a broader analysis of repartnering which takes account of other factors, including gender. Quantitative and qualitative analyses are used, with a multivariate analysis of repartnering patterns, using data from the General Household Survey, being complemented by in-depth interview data examining the attitudes of the formerly married to future relationships. The paper demonstrates that parenthood has a statistically significant effect on the likelihood of formerly married women repartnering, with a higher number of children being associated with a lower probability of repartnering. The presence of children can work against repartnering in a variety of ways. Children place demands on their parents and can deter or object to potential partners. Parents may see their parental role as more important than, and a barrier to, new relationships. However, mothers are typically looking for partners for themselves rather than fathers for their children. Among formerly married people without children, the desire to become a parent encourages repartnering. The paper concludes that parenthood should be a key consideration in analyses of repartnering.
\end{abstract}

[Keywords: Remarriage, cohabitation, divorce, lone parenthood, children.] 


\section{Repartnering: the relevance of parenthood and gender}

\section{to cohabitation and remarriage among the formerly married*}

\section{INTRODUCTION}

Compared to North America, where the formerly married and remarriage have long been the focus of research (e.g. Hunt 1966; Thornton 1977), there has until recently been a scarcity of comparable research relating to Britain, though more attention has been paid to an overlapping, but separate group, i.e. lone parents. This paper is an exploratory analysis of the impact of current and anticipated future parenthood on repartnering among people formerly living in marriage-type relationships, who are henceforth referred to as the formerly married. The paper focuses both on attitudes to future relationships and on patterns of couple formation. The emphasis on children is embedded within a broader analysis of repartnering which takes account of other factors, including gender. The term repartnering is used here to cover both remarriage and cohabitation.

Research on remarriage in North America is usually concerned with remarriages rather than the remarriage process (Coleman and Ganong 1990). Rodgers and Conrad (1986) note a lack of empirical studies of courtship before remarriage and the consequent dependence of discussions of this process on retrospective data from research on remarried families. Studies of currently divorced people (e.g. Arendell 1986; Arendell 1995; Kurz 1995) seldom emphasise repartnering, but a few notable and relevant longitudinal studies exist (Furstenberg and Spanier 1984; Spanier and Thompson 1987; Wallerstein and Kelly 1980; Wallerstein and Blakeslee 1989).

Demographic analyses of remarriage in North America, especially those using event history analysis techniques, are of particular relevance, (e.g. Koo and Suchindran 1980; Koo, et al. 1984; Teachman and Heckert 1985; Bumpass, et al. 1990; Wu and Balakrishnan 1994). Such analyses have tended to find that the presence of children and/or a greater number of 
children is linked to a lower rate of remarriage among formerly married women. However, these studies' findings are not wholly consistent, and significant variations according to age and 'race' have been noted. In addition, attention has only recently shifted from remarriage to repartnering more broadly.

Research over the last decade or so has documented demographic patterns of remarriage and repartnering in Britain (Coleman 1989; Haskey 1993; Ermisch and Francesconi 1996). As in North America, gender has been shown to be an important factor affecting the likelihood of repartnering; divorced and separated men are quicker on average to become involved in new, co-resident relationships (Coleman and Salt 1992: 206), and thus constitute markedly less than half of the formerly married, but currently single, population ${ }^{1}$.

In Britain, as in North America, previous demographic research has indicated that number of children is related to divorced women's likelihood of remarriage (Ermisch 1989; Ermisch, et al. 1990). However, though Ermisch found that having four or more children reduced the likelihood of a woman remarrying, he did not produce clear-cut findings for women with smaller numbers of children. More recent research (Clarke, et al. 1993) has suggested that the probability of remarriage is higher for women with no children than for those with one or two children. In a discussion of the impact of marital breakdown on patterns of childbearing, Diamond, et al. (1995) highlight the potential relevance of childbearing 'plans' to remarriage patterns. (Childbearing before repartnering may also have implications for the likelihood of repartnering; see Suchindran, et al. 1985). The tendency for demographic research to have paid much less attention to fatherhood than to motherhood is in part underpinned by a relative absence of data corresponding to men's fertility histories, which in turn reflects the ideological assumption that children are more central to women’s lives than to men’s.

Existing British qualitative studies involving formerly married and remarried people (e.g. Neale and Smart 1997; Burgoyne and Clark 1984; Hughes 1991) acknowledge the importance of marital histories but are in general more concerned with parenting, children's experiences and family life than they are with repartnering. Other studies (e.g. Maclean 1991) are more socio-economic in orientation, but the surveys of lone-parent families discussed by 
Bradshaw and Millar (1991) and Marsh, et al. (1997) also collected some interesting data regarding lone parents' views of and expectations regarding future partnerships. A longitudinal analysis in a related study (Ford, et al. 1998) examines exits from lone parenthood, some via repartnering, with the age of the youngest child as a covariate.

Relative to the existing literature, this paper's distinctive contribution is that, with a focus on all the formerly married in Britain, i.e. not solely on lone-parents, it examines the effect of both the presence/absence and number of children on the likelihood of women repartnering, balancing this statistical analysis with a qualitative analysis of data specifically relevant to the relationship between parenthood and repartnering. Unlike much of the existing literature, which concentrates on children's situations and experiences, this paper has couple formation as its central interest; however, unlike some analyses of couple relationships and intimacy (e.g. Giddens’ work; see Smart 1997: 312), this paper emphasises the potentially important role of children in this context.

\section{METHODS AND DATA}

This paper makes use of both quantitative and qualitative methods and data. The two approaches have their own distinctive merits, and both can make significant contributions to an understanding of repartnering. Analysis of quantitative survey data from a large, nationally representative random sample allows generalisations to be made about repartnering patterns in Britain. Analysis of qualitative data from in-depth interviews with a smaller sample of women and men provides an insight into the attitudes and experiences of the formerly married and hence facilitates an understanding of the repartnering process. We hope that this paper gives an indication of the role that qualitative data can play in providing theories which extend the results of secondary analyses of survey data by facilitating valid explanations and interpretations. Combining quantitative and qualitative approaches is not straightforward, but it can be profitable (Bryman 1988; Brannen 1992). 
The tables and multivariate analyses in this paper are based on data from the 1991/2 General Household Survey, henceforth abbreviated as GHS (OPCS 1993). Since 1971 and until recently GHS has been a continuous, annual survey of the population of Great Britain resident in private households, collecting data on a range of social policy-related topics. The 1991/2 GHS collected data from a two-stage stratified random sample of close to ten thousand households using addresses selected from the Postcode Address File, with a high response rate of over $80 \%$.

The analyses are constrained by being based on retrospective data from a cross-sectional survey. The data collected by the GHS are limited in scope: marital histories only exist for people aged 59 or under; fertility histories only exist for women aged 59 or under; the cohabitation histories collected are incomplete inasmuch as they do not include completed periods of cohabitation which did not lead to (re)marriage. The last limitation is particularly frustrating given our emphasis on repartnering rather than remarriage per se.

The quantitative section of this paper begins by considering the percentage of formerly married people who had repartnered by given durations after the end of their first marriages, according to gender, parental status and age. This is followed by a multivariate analysis which brings in a range of other factors relevant to the repartnering process. A multivariate approach allows the relationships between repartnering and each of the explanatory factors to be examined controlling for the various other factors.

Examining repartnering within a given duration, whether using percentages or more sophisticated multivariate statistical techniques such as logistic regression, necessitates the exclusion from consideration of respondents whose first marriages ended relatively recently, i.e. those respondents for whom the time elapsed since the end of their first marriages is less than the specified duration. Fortunately, a multivariate survival analysis technique such as Cox's proportional hazards model (Cox 1972; Allison 1984), which is used in this paper, allows all the relevant respondents to be included in the analysis, because it can take into account the whole period for which each respondent is or was formerly married. 
Proportional hazards models have become a standard technique for analyses of marital formation and dissolution (Koo, et al. 1984; Bumpass, et al. 1990; Heaton and Call 1995). One source of their popularity is that, unlike fully parametric techniques, they do not need the nature of the relationship between the repartnering rate and the duration spent as a formerly married person to be specified. In this paper the emphasis is on differences between the repartnering rates of different categories of formerly married people rather than the way in which the rates depend on duration. The parameters of the proportional hazards model relate to these between-category differences in repartnering rates, the assumption being that the differences remain consistently the same irrespective of the duration spent as a formerly married person ${ }^{2}$. The parameter estimates, when exponentiated, provide multiplicative factors which allow the differences in repartnering rates between groups to be assessed ${ }^{3}$. Note that the effects represented by these factors are those which remain once the other covariates in the model have been controlled for.

The proportional hazards model in this paper was fitted using SPSS for Windows, with cohabitation or remarriage as the event variable, and time to cohabitation, remarriage or the survey date as the duration variable. (The 'Indicator' contrast was used for the categorical covariates). The analysis involved 2,349 individuals, of whom 1,414 had cohabited or remarried.

While an awareness of some of the factors affecting the likelihood of repartnering can be gained from GHS data, such quantitative analyses have obvious limitations. For example, they tell us nothing about the non-co-resident relationships that formerly married people may have. More importantly, while they can identify gender differences in repartnering rates, such analyses can, for example, say nothing about gender differences in attitudes towards being involved in future relationships. Qualitative analyses can thus play an important role by helping us understand the attitudes and experiences which underpin the repartnering process

The qualitative data analysed in this paper originate from in-depth interviews with people who had been in, but were no longer in, marriages or marriage-type relationships. Fifty 
women and thirty-one men were interviewed during $1996{ }^{4}$. Pseudonyms are used in this paper to preserve anonymity.

The interviewees lived within part of the English Midlands. Various mechanisms were used to recruit them: most were recruited via advertisements and an article in local newspapers or by posters circulated locally; some heard about the research from earlier interviewees; smaller proportions were recruited via local organisations and an Electoral Register-based mailshot. The sample, though opportunistic, is socio-economically diverse. While comparisons with data from the 1991 Census Samples of Anonymised Records showed working class people to be under-represented, a sample size of 81 ensured coverage of a wide range of different socio-economic situations.

The tape-recorded interviews, lasting between 45 minutes and 4 hours, were conducted in various settings. They investigated the interviewees' views on cohabitation and remarriage, in addition to covering their marital histories and current situations. The interviews were based loosely around a topic list, but allowed the interviewees to elaborate on, and discuss in depth, issues relating to couple formation.

\section{PARENTHOOD, GENDER AND REPARTNERING}

The analyses in this section focus on repartnering (cohabitation or remarriage) after the end of first marriage through separation, divorce or death of spouse (separation rather than divorce is used to designate the end of marriage where both had occurred) ${ }^{5}$. Table I shows the percentage of GHS respondents who had repartnered by three, five and ten years after the end of their first marriage, according to sex and their age at the end of their first marriage. Increasing age at end of first marriage is on the whole associated with a decreasing probability of repartnering, though this appears less the case for men than for women, especially in the first few years. There are clear gender differences; in general, for all ages at end of first marriage, the probability of repartnering can be seen to be lower for women than 
for men, though the gender difference is negligible after three years for people whose marriages ended when they were under thirty.

The effect of children on the likelihood of repartnering can only be examined for women, because data on paternity were not collected. In addition the data only allow an investigation of the number and timing of live births to a woman, rather than the number of children living with her at and after the end of her first marriage. However, the number of births to a woman by the end of her first marriage, i.e. her parity, would seem to be an acceptable, if crude, measure. Table II shows the percentage of female GHS respondents who had repartnered by three, five and ten years after the end of their first marriage, according to their parity at the end of their first marriage. Women who had not given birth by the end of their first marriage had the greatest chance of repartnering, followed by those who had given birth once or twice, and then those who had given birth three or more times. Table III takes account of both respondents' ages and their parities at the end of their first marriages. For each age group the probability of repartnering was markedly higher for women who had not given birth by the end of their first marriage than for women who had given birth once or more by the end of their first marriage, though in the forty or over age range there are too few cases for this pattern to be statistically significant.

We now turn to the multivariate analysis of repartnering rates using Cox's proportional hazards model. Table IV shows the parameter estimates for the models fitted. The models include a range of covariates whose effects on repartnering are of interest in themselves but whose inclusion also reduces the likelihood of spurious relationships between gender, parenthood and repartnering. Among the covariates included in Model 1 are respondent's sex, and their age at the end of their first marriage. Additional covariates included in this model take account of whether the respondent was a widow/widower, their age at their first marriage ${ }^{6}$, and the year in which their first marriage ended. Finally, covariates are included relating to cohabitation before the respondent's first marriage and to the respondent's occupational class ${ }^{7}$. Model 1 also includes a number of interactions between pairs of 
covariates; other interaction terms were considered but had statistically insignificant effects. Note that when a model contains an interaction term, examinations of the effects of the two covariates involved must take into account simultaneously both the parameter estimates for the covariates and the parameter estimate corresponding to the interaction term ${ }^{8}$.

The parameter estimates for Model 1 imply that women are in general less likely to repartner than men, and indicate a decreasing likelihood of repartnering as age at end of first marriage increases. Furthermore, the difference between the repartnering rates of women and men increases with increasing age at end of first marriage. The gender difference is particularly pronounced amongst widowed people, and, as age at end of first marriage increases, the repartnering rate for widows/widowers also decreases significantly more rapidly than that for other formerly married people. The parameter estimates also indicate that, amongst the widowed, only men who are widowed at a very young age (i.e. well below the age of forty) have a repartnering rate comparable to that of their divorced/separated counterparts.

Increasing age at first marriage decreases significantly the probability of repartnering, as does the existence of a period of pre-marital cohabitation ${ }^{9}$. Socio-economic advantage in the form of occupational class is linked to a greater likelihood of repartnering, though the small number of professionally-occupied female respondents deviates significantly from this pattern. The likelihood of formerly married men repartnering increases significantly as we move towards the present but the likelihood of formerly married women doing so does not.

To summarise so far, those who repartner are disproportionately male, disproportionately relatively young, and disproportionately advantaged in terms of occupational class. In addition, those people who cohabit before their first marriages and those who marry for the first time at relatively older ages have a lower likelihood of repartnering. This second set of findings is consistent with the hypothesis that those people who were most strongly orientated towards marriage when they were single are also the most strongly motivated to repartner. 
Model 2 (see Table IV) includes a covariate corresponding to the number of children born to women by the end of their first marriages. As the number of births rises, the probability of repartnering declines sharply, with the repartnering rates for women who had given birth once or twice being about two-thirds of the rate corresponding to women who had not given birth, the rates for women who had given birth three or more times being even lower.

The interaction effect between age at end of first marriage and sex is negligible in Model 2. The magnitude and significance of this effect in Model 1 has thus been negated by the inclusion of the covariate taking account of female childbearing histories. In other words, the divergence of male and female repartnering rates with increasing age at end of first marriage implied by Model 1 relates to women's childbearing histories. Two relationships combine to induce this gender-related divergence in rates. First, the average number of births before the end of first marriage rises with increasing age at the end of first marriage. Second, for women, a higher number of births before the end of their first marriage is associated with a lower likelihood of repartnering. Taken together, the results from the two models demonstrate that as a consequence of the greater numbers of children born to them, women whose first marriages end at a relatively advanced age have a particularly low likelihood of repartnering relative to men.

Since the GHS did not collect data from men relating to the number and timing of births of children, it is not possible to compare the effects on men's and women's repartnering rates of given numbers of births before the end of first marriage ${ }^{10}$. However, comparisons can be made between the rate for men in general and the various rates for women according to the number of children born to them. In Model 2 the parameter estimate corresponding to sex is much closer to zero than it was in Model 1. This is because it relates to the difference between the repartnering rate for men and the specific repartnering rate for women who had not given birth by the end of their first marriage. This difference is much smaller than the difference between the rate for men in general and the rate for women in general. Hence the 
repartnering rate for women who had not given birth by the end of their first marriage is markedly closer to the rate for men than is the rate for all women.

Given that the majority of the children of formerly married people live with their (biological) mothers, and given the existence of other differences between motherhood and fatherhood, this comparison is arguably quite an informative one. It may be that men taken as a group are reasonably similar to childless women, and are reasonably homogeneous with respect to any relevant underlying children-related factors. If this assumption of homogeneity is correct, then the reduction in magnitude of the parameter estimate for sex between Models 1 and 2 implies that a sizeable proportion of the difference between the rates of repartnering of men and of women relates to women's childbearing histories. If the assumption is incorrect, then the reduction is simply an artefact of the absence of comparable data for men, and the whole of the gender-related repartnering differential requires some other explanation.

What is absolutely clear from Model 2, however, is that as the number of children born to them before the end of their first marriage increases, the likelihood of formerly married women repartnering decreases. There are a range of ways of explaining this. It is possible that potential partners are less interested in partnering women with dependent children, and that dependent children reduce a formerly married person's opportunities to meet potential partners (Ermisch, et al. 1990: 84). For example, among formerly married women a greater number of children may be associated with a lower rate of paid employment, thus reducing the scope for repartnering via the workplace. Alternatively, formerly married mothers are, perhaps, simply less likely to want to repartner. Other explanations emphasise the effects of smaller numbers of children: an absence (or small number) of children may act as an incentive to cohabit or remarry either in order to provide a normatively appropriate context within which to have (more) children, or simply in order to provide a 'significant other' as a source of intimacy and emotional support.

The GHS provides evidence relating to younger formerly married women which appears consistent with this latter type of explanation. Female respondents were asked whether they thought that they would have more children. Less than one in fifty (3/206) formerly married 
women aged between thirty-five and forty-four said that they thought that they would probably have more children. Conversely, four out of five (30/37) aged under thirty-five who had not had children said that they thought that they would. This contrasts with a figure of less than one in five (32/163) for those aged under thirty-five who had had one or more children $^{11}$.

Some formerly married women who want further children may only wish to have them in the context of a co-resident couple relationship. For such women there is a clear incentive to cohabit or remarry. Unfortunately, a snag with the above findings is that the expectation of having further children may have been generated in some cases by a non-co-resident couple relationship. In addition, while the expectation of further childbearing appears minimal among formerly married women above the age of forty, the multivariate analysis suggests that the higher rate of repartnering for childless women is still present for women aged over forty at the end of their first marriages ${ }^{12}$. Arguably, this directs attention back to the explanations focusing on children as a disincentive to repartner or as a disincentive in the eyes of potential partners, or alternatively to the explanation relating to the desire for a 'significant other', i.e. someone with whom to have a close and emotionally supportive relationship.

This section has shown that the likelihood of repartnering varies among the formerly married according to age, gender, class, and marriage and parental status-related factors. A key finding is that, for formerly married women at least, parenthood has a significant effect on the likelihood of repartnering. While the underlying explanations for this effect are difficult or impossible to establish using GHS data, the qualitative data in the following section cast some light on the issues.

\section{ATTITUDES TO REPARTNERING}


Research based solely on secondary analyses of quantitative data is liable to make assumptions about attitudes, motives and decisions which, though often plausible, lack the empirical grounding that can be provided by qualitative accounts. For example, it is often assumed that all formerly married people are looking for marital or cohabiting relationships, and that women are less successful than men in securing such relationships, rather than, perhaps, having less to gain from them. In the following sections the relevance of current and future parenthood to formerly married people's perspectives on future relationships is examined, together with the views of the formerly married on potential partners who have children, and the views of formerly married people's children, as perceived and reported by their parents.

\section{Parental status and attitudes to future relationships}

Though most of the interviewees wanted to have a co-resident relationship in the future, a significant proportion of them favoured (or in a few cases were in) non-co-resident relationships. The idea of living with someone again was uninteresting to some interviewees, as the new-found freedoms in their lives and the power of self-determination (a new experience for many who had left the parental home to live in the marital home) were too valuable to give up. The following response was typical:

'... so it's hard enough coping with two children, to be quite honest, without having to cope with somebody else. Of course, I know it wouldn't mean anybody else. Ideally, you'd have a relationship where it didn't mean moving in. I would like to think that I didn't feel the need to be supported by anybody else' (Carol: divorced and in her midforties with two dependent children.)

For those with children, like Carol, the thought of coping with someone else as well as their children was often too much to contemplate. 
Echoing the quantitative finding that many formerly married women without children expected to have one or more in the future, all five female interviewees without children, who were all under forty, either wanted or possibly wanted children in the future (as did two of the three men who had not had children). For some women who wanted children finding a partner to have them with was crucial. Susie said:

'I couldn't have a child as a single person, so I would be very, very careful again about having it and I would really only want it in the realms of a marriage relationship, because I know that I don't think I would want to cope with it on my own, to cope with a child on my own... given the choice, I don't think I could cope on my own. I would rather cope within a relationship, a marriage relationship, a team relationship and I know it causes a lot more hardship... but still it's a really big part of a relationship, but there again, who knows, maybe I won't be able to have any’ (Susie: divorced and in her mid-twenties with no children.)

None of the women under thirty without children felt there to be any hurry to have children, though all emphasised time constraints. As Stephanie said:

'I need to sort myself out first and have a clue about what I'm going to do and then I would like to have a child of my own. I wouldn't like to have a child when I'm very old, you know, in my forties, but I have friends who have [had] children when they're forty and it wasn't a problem' (Stephanie: an ex-cohabitee in her early twenties with no children.)

Age does eventually become a constraint. The biological constraint of the menopause is coupled with an ideological constraint: the ageist idea that women in later life might be too old to cope with young children.

Anne emphasised this point: 
'With being young there is the added advantage [that] you have got energy. At [my age] now to have another one... just the physical strength needed. I don't think men realise the amount of energy you do need to bring up a family' (Anne: divorced and in her mid-thirties with two dependent children.)

Such attitudes were, however, not echoed by the men without children. Rob, a childless man in his mid thirties, felt no time pressure to have children. He said:

'I'm [in my mid-thirties] now... I've never thought [before] about settling down before I'm forty, or having children before it's too late, that's never occurred to me' (Rob: an ex-cohabitee.)

However, men with children were generally loathe to have more children in the future since they felt that they would be unable to be as good at parenting as they were when they were younger.

It seems that men are not free of pressures to have children when they are younger; such pressures often come from family and friends. As Paul said:

'My father's okay about it, you know, he says things like you can have children when you're sixty-five, you know, it doesn't matter. He's not worried, my mother's probably worried more for me, that I'm not married, you know, and I'm [in my mid-thirties] and not going to bear her grandchildren' (Paul: an ex-cohabitee in his mid-thirties with no children.)

While women face biological constraints on childbearing, cultural barriers to having children in later life can affect both women and men, though the childless men interviewed implied that they would be 'good' fathers at any age, whereas the women without children suggested 
that they would make better mothers when 'younger' (i.e. in their twenties or thirties). Individuals' own views can be reinforced by the attitudes of those around them. For those who want children, cultural barriers can intensify the desire to find a partner quickly with whom to have children; conversely, they may deter those who find a partner relatively late in life from having much-wanted children. The pressures to have children at a relatively early age, coupled with attitudes promoting having children in a stable couple relationship, can lead to an increasingly desperate search for a partner.

Gender role ideology meant that for some women the role of wife and mother was very important indeed, and the removal of both aspects of this role led to anxiety:

'I'd always wanted to be a wife and a mother, that's the role I know. All right, the kids would have left and I'd still be the wife, I'd still have a role. I don't have a role and that's one of the things that I'm having difficulty coming to terms with. It's all very well saying you can do what you like. I don't know what I want to do...' (Davina: divorced and in her early fifties with non-resident children over sixteen.)

Only one male interviewee reflected similarly on the loss of his past roles as husband and resident father.

While the presence of children is positive for some women both before and after separation or divorce it can also impact on women's lives in negative ways. For example, the relative poverty of female lone-parents was mentioned by a number of the women interviewed. The following response was typical: 
'But their [men's] recovery is easy... because they can go out any place socially on their own, a certain amount of freedom to come and go as they choose. Probably they've got a little bit more money as well, which again is helpful, and they may have children, or whatever, but they have more options of getting on with their lives. If you're a woman who's left the children and got a baby-sitter, money, women do care about their appearance and if you haven't got a lot of money, the money goes on the food first, clothes, your hair, to get hair cut nowadays costs a fortune...' (Anne: divorced and in her mid-thirties with two dependent children.)

Financial constraints affect women's experiences of lone-parenthood and their opportunities for securing a relationship if they want one. On child-rearing women often forego the straightforward career path on which they could accumulate experience and skills (Maclean 1991: 95). This affects earnings which, coupled with often low maintenance payments and benefits, means that female lone parents are especially likely to live in poverty. Scarce resources are devoted primarily to children and necessities, leaving little to spend on luxuries such as personal appearance. This may further undermine self-esteem and make meeting a new partner seem virtually impossible.

The desire to become a parent combined with cultural and family pressures encourages repartnering. These pressures, along with biological constraints, also encourage repartnering sooner rather than later, especially for women. However, the presence of children can reduce the desire to repartner by providing formerly married people with a parenting role, and can hinder repartnering by placing time and money demands on female lone-parents whose opportunities for repartnering are undermined by cultural, occupational, financial and temporal constraints. 
Attitudes to future relationships can be affected if a prospective partner has children. Most interviewees had considered this as a possibility, and many felt that it might cause some difficulties. As Susie said:

'That would be hard. I think that would be hard... That's a viewpoint I've been seeing because obviously I'm getting older, and the age range that I'm looking at is getting older, and most of them have got children... I don't know whether I would take on somebody else's children. I suppose if I loved them enough then I would be prepared to take them on, but I think it's a very hard thing to do... I don't know. I don't think I'd be able to make that decision without finding the person really' (Susie: divorced and in her mid-twenties with no children.)

As a formerly married person gets older the likelihood of their finding someone of their own age without children decreases, and it may be that the attitudes of formerly married people to prospective partners with children change as time passes. Nearly half of the women interviewed, and also of the men, said that they would not mind having a relationship with someone with children in the future, but there were important gender differences. None of the women with children said that they were prepared to have a relationship with a man with young, dependent children; they said that they did not want to look after young children again. However, most felt more positive about having a partner with older children. Julia's response was typical:

'...I wouldn't mind that. Frank's got two children and we only see one of them now... He's grown up, so he's not a child. So I'm not like a wicked stepmother, because we've 
got nothing to do with him' (Julia: divorced and in her early forties with two dependent children.)

The cultural stereotype of the wicked stepmother (Hughes 1991), coupled with a disinclination to repeat the experience of parenting young children, make the prospect of having a relationship with a person with older children comparatively attractive.

While women were disinclined to take on the responsibility of caring for younger children, men were concerned about the financial supporting role:

'I wouldn't [have a relationship with a lone mother] because I'm sure there are genuine cases out there, but... I think it's an easy way out for some people who have had kids and either they're on social or getting whatever they can free. I don't have a high regard for that' (Rob: an ex-cohabitee in his mid-thirties with no children.)

Many of the women with children knew of men who felt like this, however, they asserted that this attitude was not based on reality. As Anne said:

'I'm not looking for a father for my children; they've already got a dad. I'm looking for a partner for me. There's a difference. If I had younger children, then I might be looking for someone to take on the role of a father and a partner for me, but with my children being the age that they are, they don't need a father, they've got a father, they've got a dad. That's something that you have to work at' (Anne: divorced and in her mid-thirties with two dependent children.)

Though looking for a partner for herself, Anne's implicit suggestion is that younger children need a resident father figure, and that this might be a consideration for mothers of younger children. However, one woman was loathe to share her children with a man and, indeed, this had had a negative effect on a previous relationship: 
'I suppose I'd be jealous if my children gave somebody else affection. I know that's the wrong thing to say, but it's an honest thing to say. I would find it very difficult to let them... I don't want a father substitute for them. Bob wanted to be a father substitute, and he wanted to be a dad, and that worried me' (Jackie: an ex-cohabitee in her early thirties with a number of dependent children.)

A number of the interviewees delayed divorce until their children were older and consequently did not have very young children for whom a future partner could become a replacement parent. As Julia said:

'...it was just a set of circumstances that my children were only about five and eight, and this man wanted me to leave them and go away with him, and I'd only known him for three months, and I couldn't, because I'm quite a practical person and, well, I couldn't leave my kids anyway at that age. I mean I could now, but I couldn't then’ (Julia: divorced and in her early forties with two dependent children.)

Staying with children until they were thought old enough to cope with the break-up was a pattern displayed on occasions by both women and men. This, of course, meant that by the time they left the marital home they were older themselves. Since repartnering rates decrease with increasing age, parents, especially women, who prioritise their parenting role above their own needs and desires might be running the risk of sacrificing their own future happiness.

A concern about life after the child-rearing years was for some an incitement to split up.

As Ian said:

'...I got to the age of forty where I was thinking "In ten years time the kids will go and how are we going to sit and look at each other across the dinner table?”. That was the 
worst thing, and even if we'd kept it together for the kids, to sort of, you know... how you can possibly sit and live out your lives after that. So is it better to go now, and give each other the chance to make something out of our lives, or is it best to keep it together, like, that falsely...' (Ian: separated and in his early forties with non-resident children under sixteen.)

A number of male interviewees referred to the impact of the Child Support Agency (CSA) on women's attitudes to having a relationship with them. As John said:

'I had a relationship with somebody last summer who was really quite paranoid about that [living with me] because she was on low pay and with the CSA laws they take that [her income] into account and if she [mother of child] had found out she would have shopped me straight away’ (John: an ex-cohabitee in his early thirties with two non-resident children under sixteen.)

Most interviewees had reservations about becoming involved with potential partners with dependent children because of the responsibilities involved. Many women did not want to assume the role of caring for children again; some men were wary about providing economic support for lone mothers' children. Older children were viewed less negatively. The perceived attitudes of prospective partners sometimes undermined the confidence of interviewees with children about their chances of repartnering. Among interviewees with children, attitudes to splitting up and repartnering depended on the perceived importance of couple relationships and the centrality of their roles as parents. We turn next to the children's views, as perceived by their parents.

Attitudes of children

All the interviewees with children considered the attitudes of their own children to them finding a partner. Women often had children living with them, whereas men often had 
visiting rights to children. Women with younger children said they felt constrained and were worried about taking a man home. The following response was typical:

'I don't really want them to meet every Tom, Dick and Harry, do you know what I mean, but the ones that they do know they get on well with. Some people sort of have blokes coming in and out of their lives all the time and the kids meet - and I think that would be traumatic, no matter what age the child is, if they're young or even older' (Anne: divorced and in her mid-thirties with two dependent children.)

Worrying about their reputation with their children, family and neighbours was mentioned by a number of the women interviewed and, as mothers, they felt they should not be seen to be having relationships with different men. Older children could be just as difficult as younger children. This was emphasised by a man with a dependent daughter:

'She's now fifteen. So certainly in those three years... it would be intolerable if I was going out with somebody that was not accepted either from one side or the other. Yes, definitely it's got to be an acceptable relationship between my partner and my daughter, and my daughter and my new partner' (Giles: divorced and in his mid-fifties with a dependent child.)

Waiting until children were older or moved away was a strategy considered by a number of interviewees, though some found that even children who no longer lived with them still felt they had a right to comment on their parents' relationships. This was articulated as being for the parents’ protection; Jill’s response was typical:

'They think he's [present boyfriend] a waste of space, to put it quite finely, because... they know how he feels about other women. My daughter does get very irate about it 
every now and then. She says "I won't interfere in your life”. She says that "When you're out with Eric... you're happy”. She says that "I also know what it does to you with his female friends”, and she says "I hate him for it”. There's no other way to put it. My son wasn't very happy, although they're both very, very pleasant to him and they respect the fact that if it was to be my choice, it's my choice and not theirs' (Jill: widowed and in her mid-forties with non-resident children over sixteen.)

Non-resident children also affected men's scope for having relationships. As Adam said:

'You then work out a structure whereby you can operate with children moving to and fro, etc., and then you think you've got that sorted out when Christmas arrives, and so I think that even when you get sorted out there are key times that are very difficult, and I think times like Christmas is certainly one of them. I think holidays is another one... I don't see them every day of the week any more, so when I do see them, they're all mine, I want to have all that time' (Adam: divorced and in his early forties, with sometimes-resident dependent children under sixteen.)

The desire to devote as much time as possible to visiting or caring for children creates disruptions and demands on time which affect an individual's ability to have couple relationships.

Children's attitudes can hamper a formerly married person's search for a future partner, as can time devoted to visiting non-resident children. Formerly married parents do not want to upset their children or give them mixed messages, and are often keen to avoid damaging their public reputations.

DISCUSSION AND CONCLUSIONS: CHILDREN, GENDER AND FUTURE RELATIONSHIPS 
This paper has shown that the likelihood of a formerly married woman cohabiting or remarrying decreases as the number of children born to her before the end of her first marriage increases. This quantitative finding indicates that the presence (or absence) of children is an important factor to consider in any analysis of repartnering. In addition, the qualitative analysis in this paper emphasises the frequent centrality of children to formerly married people's perspectives on repartnering and helps us to understand the observed statistical relationship.

Relationships with children may take priority over a new couple relationship, and thus act as a barrier to, or even eliminate the 'need' for, such a relationship. A new partner may be viewed as a source of extra demands, similar and additional to children's demands, and the perceived disadvantages of a co-resident relationship may thus outweigh the perceived advantages, resulting in a wary attitude towards cohabitation or remarriage. However, while attitudes to future relationships are usually affected by children, they are not wholly determined by them. For example, formerly married women with children typically appear to be looking for partners for themselves rather than fathers for their children.

The economic and social responsibilities placed on formerly married people by co-resident children may restrict their ability to search for new partners. Children living elsewhere can still act as a constraint by placing demands on their finances, time and energy. Children can also deter potential partners; they can be perceived as a potential burden in financial or caring terms, or can cast doubt on the formerly married person's motives for seeking a relationship. The interviews indicate that cultural norms relating to promiscuity can act as a constraint on the sexual behaviour of some formerly married people with children; earlier research has indicated that formerly married women are frequently concerned about the impact of their sexual activities on their children (e.g. Arendell 1986: 141).

While the quantitative analyses focuses on cohabitation or remarriage, the interviews highlight the importance of non-co-resident couple relationships. It is possible that formerly 
married people who become involved in non-co-resident relationships because of concerns relating to their children (or, indeed, for other reasons) may adjust to this lifestyle and become progressively less likely to cohabit or remarry. The assumption that non-co-resident relationships belong to a transitional stage preceding cohabitation or remarriage reflects a tendency to map norms corresponding to the pre-marital period onto the post-marital period. We need to ask whether the first marriage and remarriage processes are really that similar.

The interviews highlighted the fact that being 'on their own' is a novel experience for some of the formerly married. This situation is often perceived positively, but one might hypothesise that in some cases unfamiliarity with the situation may act as an incentive to change it. The quantitative analyses showed age at first marriage (more precisely, age at cohabitation with first marriage partner) to have a significant effect on the likelihood of cohabitation or remarriage. This may reflect heterogeneity in the degree to which individuals are positively orientated towards couple relationships, with those who are not used to living alone being more keen to establish a new live-in relationship.

Various sources of heterogeneity in the likely effects of children were evident from the qualitative interviews. The age and location of children appear to be of relevance, both in terms of the perception of a prospective partner as a 'substitute' for the absent biological parent, and in terms of the extent to which children act as a deterrent to potential partners. Formerly married people prioritise their children's views and well-being over their own gratification to different extents. We might hypothesise that those who delay ending marriages for the sake of their children are disproportionately those who do not see a good couple relationship as an essential feature of their lives.

It is interesting to contrast those formerly married people who still have plans for more children with those who have 'completed their families'. The quantitative analyses suggest that a desire to have children may act as an incentive to cohabit or remarry, and the qualitative data provide qualified confirmation of this. Conversely, the disinclination of some women to form relationships with men with young children is tied to a sense that they have already been through the relevant life-course stage. Normative assumptions that suggest that 
women should marry to provide an appropriate context within which to have children are irrelevant to women who do not want to have more children; any cultural and economic incentives women might have to remarry which relate to having additional children are absent for women who have completed the family formation stage of the life-course.

Ideological assumptions relating to life-course stages can also be relevant to the perceptions of formerly married people regarding the appropriateness of seeking a new partner at a given age. Certainly, some interviewees were of the opinion that the social opportunities for them to meet potential partners were more limited than 'first time around'. Whatever their feelings were about the appropriateness of seeking partners, it was clear to them that society was not structured in a way that made it easy for them to do so. Repartnering patterns thus reflect constraints as well as choices; parenthood and gender affect both preferences and constraints. 
NOTES

* This paper is a revised version of a paper presented at the British Society for Population Studies 1996 annual conference held at St. Andrews, and is based on research carried out as part of a broader project focusing on the formerly married, The Remarriage Process: Structural and Individual Perspectives. The authors wish to express their gratitude for the funding received from the Economic and Social Research Council (Research Grant No. R000236057). For further details of the research, see Lampard (1997). Material from the General Household Survey made available through the Office of Population Censuses and Surveys (now the Office for National Statistics) and the ESRC Data Archive has been used by permission of the Controller of HM Stationery Office. This paper also contains results based on the SARs provided through the Census Microdata Unit of the University of Manchester with the support of the ESRC/JISC/DENI. The authors bear sole responsibility for the further analyses and interpretations of the above material.

1. Data from the 1991 Census (Samples of Anonymised Records [SARs]; Household sample) indicate that only $36 \%$ of formerly married people under 60 (who are not currently cohabiting) are men. This percentage rises to 39\% if widowed people are excluded.

2. Proportional hazards models are of the form

$$
\mathrm{h}\left(\underline{z}_{\mathrm{i}}, \mathrm{t}\right)=\mathrm{h}_{0}(\mathrm{t}) \exp \left\{\underline{\mathrm{z}}_{\mathrm{i}}{ }^{\mathrm{T}} \underline{\underline{\beta}}\right\}
$$

where $\mathrm{h}\left(\underline{z}_{\mathrm{i}}, \mathrm{t}\right)$ is the 'hazard' (risk) for individual i at time $\mathrm{t}, \mathrm{h}_{0}(\mathrm{t})$ is a common/baseline hazard function applying to all individuals, $\underline{z}_{i}$ is a vector of covariates for individual $i, \underline{\beta}$ is a vector of coefficients for these covariates, and $\exp \left\{\underline{z}_{i} \underline{T}_{\underline{B}}\right\}$ is therefore a factor relating to the risk for individual i relative to the baseline hazard.

3. For example, the exponentiated value of 1.208 for Class I or II people in Model 1 (see Table IV) implies that the repartnering rate for Class I or II people is $20.8 \%$ higher than that 
for the base category (people in Class III), and the corresponding figure of 0.950 for age at first marriage implies that the repartnering rate decreases by $5 \%$ for an additional year of age at first marriage.

4. Transcripts of 32 interviews were available when the qualitative analysis reported in this paper was originally carried out. The analysis is thus based primarily on these interviews, which involved 21 women and 11 men aged between 23 and 70, of whom 10 were excohabitees, 3 were separated, 16 were divorced, and 3 had been widowed. Three-quarters had had children, but only 10 (mainly divorced women) were living with dependent children.

5. Note that data were unavailable regarding: (i) completed cohabitation spells which did not lead to remarriage; (ii) formerly married people who died before cohabiting or remarrying. The level of accuracy was one month for most of the data.

6. Age at first marriage was replaced by age at cohabitation for respondents who cohabited pre-maritally. Marriage duration was not included as a covariate because it is identical to the difference between age at marriage and age at the end of marriage (see Wu and Balakrishnan 1994).

7. The pre-marital cohabitation covariate is a dummy variable. The respondent's occupational class is based on their own current or most recent occupation, classified using Registrar General’s Social Class.

8. For example, the gender effect in Model 1 is -0.398 for divorced/separated people, but is -0.942 (i.e. the sum of -0.398 and -0.544 ) for widowed people. In both cases these effects correspond specifically to people whose marriages ended at the age of thirty in 1980, i.e. people with the 'base' values for age at end of marriage and for the year in which marriage 
ended. Hence the gender effect for divorced/separated people whose marriages ended at the age of forty in 1970 is $-0.398+(10 x-0.018)+(-10 x-0.015)=-0.428$.

9. This differs from the effect reported by Wu (1995), probably at least in part because of the limited cohabitation data available: see Footnote 5. Note that the effects of pre-marital cohabitation and of age at first marriage exist independently of each other.

10. Even if such data were available, the possibility that number of births acts as a proxy for number of resident children post-separation (or for a desire for additional children) would complicate the interpretation of such comparisons.

11. These findings again relate to numbers of live births. A near-identical pattern is found using numbers of dependent children.

12. It was hypothesised that the effect on repartnering of the number of births by the end of the first marriage might vary according to age at the end of the first marriage, but the addition to Model 2 of the relevant interaction term did not provide any evidence in support of this hypothesis. 
BIBLIOGRAPHY

Allison, P.D. 1984 Event History Analysis: Regression for Longitudinal Event Data (Series QASS No. 46), London: Sage.

Arendell, T. 1986 Mothers and Divorce: Legal, Economic and Social Dilemmas, London: University of California.

Arendell, T. 1995 Fathers and Divorce, London: Sage.

Bradshaw, J. and Millar, J. 1991 Lone Parent Families in the UK, Department of Social Security Research Report No. 6, London: HMSO.

Brannen, J. (ed.) 1992 Mixing Methods: Qualitative and Quantitative Research, Aldershot: Avebury.

Bryman, A. 1988 Quantity and Quality in Social Research, London: Unwin Hyman.

Bumpass, L., Sweet, J. and Martin, T.C. 1990 'Changing patterns of remarriage’, Journal of Marriage and the Family52.3: 747-756.

Burgoyne, J. and Clark, D. 1984 Making a Go of It: A Study of Stepfamilies in Sheffield, London: Routledge and Kegan Paul.

Clarke, S., Diamond, I., Spicer, K. and Chappell, R. 1993 'The relationship between marital breakdown and childbearing in England and Wales’ in Ní Bhrolcháin, M. (ed.) New Perspectives on Fertility in Britain: Studies on Medical and Population Subjects, 55, London: HMSO.

Coleman, D.A. 1989 'The Contemporary Pattern of Remarriage in England and Wales' in Grebenik, E., Hohn, C. and Mackensen, R. (eds) Later Phases of the Family Cycle: Demographic Aspects, Oxford: Clarendon Press.

Coleman, D. and Salt, J. 1992 The British Population: Patterns, Trends and Processes, Oxford: Oxford University Press. 
Coleman, M. and Ganong, L.H. 1990 'Remarriage and stepfamily research in the 1980s: increased interest in an old family form', Journal of Marriage and the Family52.4: 925-940.

Cox, D.R. 1972 'Regression models and life-tables' (with discussion), Journal of the Royal Statistical Society (Series B) 74: 187-220.

Diamond, I., Clarke, S. and Clarke, P. 1995 'The Impact of Marital Breakdown on the Quantum and Tempo of Childbearing in England and Wales', Paper prepared for the European Population Conference, Milan, September 4-8.

Ermisch, J. 1989 'Divorce: Economic Antecedents and Aftermath’ in Joshi, H. (ed.) The Changing Population of Britain, Oxford: Basil Blackwell.

Ermisch, J. and Francesconi, M. 1996 'Partnership Formation and Dissolution in Great Britain', Working Papers of the ESRC Research Centre on Micro-social Change Paper 96-10, Colchester: University of Essex.

Ermisch, J., Jenkins, S. and Wright, R. 1990 'Analysis of the Dynamics of Lone Parenthood: Socio-Economic Influences on Entry and Exit Rates' in OECD. Lone-Parent Families: The Economic Challenge, Paris: OECD.

Ford, R., Marsh, A. and Finlayson, L. 1998 What Happens to Lone Parents: A Cohort Study 1991-1995, Department of Social Security Research Report No. 77, London: The Stationery Office.

Furstenberg, F. and Spanier, G. 1984 Recycling the Family: Remarriage after Divorce, Beverly Hills: Sage.

Haskey, J. 1993 'First marriage, divorce and remarriage: birth cohort analyses', Population Trends 72: 24-33.

Heaton, T.B. and Call, V.R.A. 1995 'Modeling family dynamics with event history techniques', Journal of Marriage and the Family57.4: 1078-1090.

Hughes, C. 1991 Stepparents: Wicked or Wonderful?, Aldershot: Avebury.

Hunt, M. 1966 The World of the Formerly Married, New York: McGraw-Hill. 
Koo, H.P. and Suchindran C.M. 1980 'Effects of children on women's remarriage prospects', Journal of Family Issues 1.4: 497-515.

Koo, H.P., Suchindran, C.M. and Griffith, J.D. 1984 'The effects of children on divorce and remarriage: a multivariate analysis of life table probabilities’, Population Studies 38.3: 451-471.

Kurz, D. 1995 For Richer, For Poorer: Mothers Confront Divorce, London: Routledge.

Lampard, R. 1997 The Remarriage Process: Structural and Individual Perspectives, End of Award Report, Swindon: Economic and Social Research Council.

Maclean, M. 1991 Surviving Divorce: Women's Resources after Separation, London: Macmillan.

Marsh, A., Ford, R. and Finlayson, L. 1997 Lone Parents, Work and Benefits. The first effects of the Child Support Agency to 1994, Department of Social Security Research Report No. 61, London: The Stationery Office.

Neale, B. and Smart, C. 1997 ‘Experiments with parenthood?’, Sociology31.2: 201-219.

Office of Population Censuses and Surveys (Social Survey Division). 1993 General Household Survey 1991, Series GHS No. 22, London: HMSO.

Rodgers, R.H. and Conrad, L.M. 1986 'Courtship for remarriage: influences on family reorganization after divorce’, Journal of Marriage and the Family48.4: 767-775.

Smart, C. 1997 'Wishful Thinking and Harmful Tinkering? Sociological Reflections on Family Policy’, Journal of Social Policy26.3: 301-321.

Spanier, G. and Thompson, L. 1987 Parting: the Aftermath of Separation and Divorce, Beverly Hills: Sage.

Suchindran, C.M., Koo, H.P. and Griffith, J.D. 1985 'The effects of post-marital childbearing on divorce and remarriage: an application of hazards models with timedependent covariates’, Population Studies 39.3: 471-486. 
Teachman, J.D. and Heckert, A. 1985 'The impact of age and children on remarriage: further evidence', Journal of Family Issues 6.2: 185-203.

Thornton, A. 1977 'Decomposing the remarriage process', Population Studies 31.2: 383392.

Wallerstein, J. and Blakeslee, S. 1989 Second Chances: Men, Women and Children a Decade after Divorce, London: Bantam.

Wallerstein, J. and Kelly, J. 1980 Surviving the Breakup: How Children and Parents Cope with Divorce, London: Grant Macintyre.

Wu, Z. 1995 'Premarital cohabitation and postmarital cohabiting union formation', Journal of Family Issues 16.2: 212-232.

Wu, Z. and Balakrishnan, T.R. 1994 'Cohabitation after marital disruption in Canada', Journal of Marriage and the Family56.3: 723-734. 
TABLE I: Repartnering by the formerly married according to duration, age at end of first marriage and sex (percentages)

Had repartnered by 3 years

Age at end of first marriage

Women

(N)

Men

(N)

All

16 - 29 years

40.3

(621)

41.1

(367)

40.6

30 - 39 years

31.2

42.0

36.1

40 - 49 years

17.6

36.4

25.6

50 - 59 years

0.0

(26)

41.2

(17)

16.3

$\underline{\text { Had repartnered by } 5 \text { years }}$

\section{Age at end of}

first marriage

Women

(N)

Men

(N)

All

16 - 29 years

55.5

(542)

64.0

58.7

30 - 39 years

46.4

54.9

50.2

40 - 49 years

23.1

48.8

33.5

50 - 59 years

7.1

46.2

25.9

Had repartnered by 10 years

Age at end of first marriage

Women

(N)

Men

(N)

All

16 - 29 years

75.5

(417)

83.3

(245)

78.4

30 - 39 years

53.5

(226)

67.2

(189)

59.8

40 - 49 years

35.2

(71)

56.3

(48)

43.7

50 - 59 years

Source: 1991/2 General Household Survey (Authors’ analysis). 
TABLE II: Repartnering by formerly married women according to duration and number of children (percentages)

Number of

children

(live births) After 3 years

$\begin{array}{ll}0 & 48.3 \\ 1 & 32.6 \\ 2 & 30.5 \\ 3 & 21.4 \\ 4+ & 23.3\end{array}$

$\begin{array}{rr}(298) & 63.4 \\ (258) & 48.2 \\ (354) & 45.4 \\ (173) & 34.3 \\ (90) & 31.3\end{array}$

63.4

8.2

4.4

4.3

1.3

Source: 1991/2 General Household Survey (Authors’ analysis).
(N) After 10 years (N)

$\begin{array}{rrr}(262) & 79.7 & (192) \\ (224) & 62.7 & (161) \\ (302) & 62.1 & (203) \\ (140) & 53.3 & (107) \\ (83) & 47.1 & (51)\end{array}$


TABLE III: Repartnering by formerly married women according to duration, age at end of first marriage and number of children (percentages)

No children (live births)

$\begin{array}{lrrrrrr}\begin{array}{l}\text { Age at } \\ \text { end of } \\ \text { marriage }\end{array} & \text { After 3 years } & (\mathrm{N}) & \text { After } 5 \text { years } & (\mathrm{N}) & \text { After } 10 \text { years }(\mathrm{N}) \\ & & & & & & \\ 16-29 \text { years } & 51.3 & (224) & 67.0 & (197) & 83.4 & (151) \\ 30 \text { - 39 years } & 45.0 & (60) & 56.4 & (55) & 66.7 & (39) \\ 40 \text { - 59 years } & 14.3 & (14) & 30.0 & (10) & 50.0 & (2)\end{array}$

$\underline{\text { One or more children (live births) }}$

$\begin{array}{lcccccr}\begin{array}{l}\text { Age at } \\ \text { end of } \\ \text { marriage }\end{array} & \text { After 3 years } & (\mathrm{N}) & \text { After } 5 \text { years } & (\mathrm{N}) & \text { After } 10 \text { years }(\mathrm{N}) \\ & 34.0 & (397) & 49.0 & (345) & 71.1 & (266) \\ 16-29 \text { years } & 28.6 & (318) & 44.4 & (279) & 50.8 & (187) \\ 30-39 \text { years } & 15.0 & (160) & 20.8 & (125) & 34.8 & (69) \\ 40-59 \text { years } & & & & & \end{array}$

Source: 1991/2 General Household Survey (Authors’ analysis). 
TABLE IV: Proportional hazards models of repartnering by the formerly married (parameter estimates)

\section{Variable (or}

interaction term)

\section{Model 1}

Sex

Widowed

Pre-marital cohab.

Age (end of m'ge)

Age (at first m'ge)

Year (end of m'ge)

Class I or II

Class IV or V

Class I woman

Age (end of m'ge)

* Sex

Year (end of m’ge)

* Sex

Widowed

* Sex

Age (end of m'ge)

* Widowed

No. of children\#

1 child

2 children

3 children

4+ children
B $\quad$ S.E. P $\quad \operatorname{Exp}(B)$

$\begin{array}{llll}-0.398 & 0.061 & 0.000 & 0.672\end{array}$

$\begin{array}{llll}0.120 & 0.209 & 0.567 & 1.127\end{array}$

$\begin{array}{llll}-0.266 & 0.079 & 0.001 & 0.767\end{array}$

$\begin{array}{llll}-0.019 & 0.006 & 0.003 & 0.981\end{array}$

$\begin{array}{llll}-0.052 & 0.010 & 0.000 & 0.950\end{array}$

$\begin{array}{lllll}0.022 & 0.006 & 0.000 & 1.022\end{array}$

$\begin{array}{lllll}0.189 & 0.063 & 0.003 & 1.208\end{array}$

$\begin{array}{lllll}-0.257 & 0.069 & 0.000 & 0.773\end{array}$

$\begin{array}{llll}-0.578 & 0.283 & 0.041 & 0.561\end{array}$

$\begin{array}{llll}-0.018 & 0.008 & 0.028 & 0.983\end{array}$

$\begin{array}{llll}-0.015 & 0.007 & 0.036 & 0.985\end{array}$

$\begin{array}{llll}-0.544 & 0.255 & 0.033 & 0.581\end{array}$

$\begin{array}{llll}-0.047 & 0.014 & 0.001 & 0.954\end{array}$
Model 2

B S.E. P $\quad \operatorname{Exp}(B)$

$\begin{array}{llll}-0.031 & 0.081 & 0.703 & 0.970\end{array}$

$\begin{array}{llll}0.128 & 0.208 & 0.538 & 1.136\end{array}$

$\begin{array}{lllll}-0.276 & 0.079 & 0.001 & 0.759\end{array}$

$\begin{array}{llll}-0.015 & 0.006 & 0.016 & 0.985\end{array}$

$\begin{array}{llll}-0.068 & 0.010 & 0.000 & 0.935\end{array}$

$\begin{array}{lllll}0.022 & 0.006 & 0.000 & 1.022\end{array}$

$\begin{array}{lllll}0.174 & 0.063 & 0.005 & 1.191\end{array}$

$\begin{array}{llll}-0.215 & 0.069 & 0.002 & 0.807\end{array}$

$\begin{array}{llll}-0.667 & 0.284 & 0.019 & 0.513\end{array}$

$\begin{array}{llll}-0.002 & 0.008 & 0.797 & 0.998\end{array}$

$\begin{array}{llll}-0.016 & 0.007 & 0.026 & 0.984\end{array}$

$\begin{array}{llll}-0.554 & 0.255 & 0.030 & 0.575\end{array}$

$\begin{array}{llll}-0.052 & 0.014 & 0.000 & 0.950\end{array}$

------ ------ $0.000 \quad------$

$\begin{array}{llll}-0.389 & 0.100 & 0.000 & 0.678\end{array}$

$\begin{array}{llll}-0.491 & 0.099 & 0.000 & 0.612\end{array}$

$\begin{array}{llll}-0.784 & 0.140 & 0.000 & 0.456\end{array}$

$\begin{array}{llll}-0.790 & 0.184 & 0.000 & 0.454\end{array}$

Notes:

*: Denotes interaction term.

\#: Number of live births by the end of first marriage.

$\mathrm{B}=$ Parameter estimate; S.E. $=$ Standard error; M'ge = Marriage.

$\mathrm{n}=2,349$ (of whom 1,414 repartnered).

The omitted (base) categories for the categorical variables are: male, not widowed, did not cohabit before first marriage, Class III or unclassified, not a Class I woman, and no children (live births).

Age at end of marriage and year of end of marriage were recalibrated so that 30 and 1980 were treated as zero values, hence, for example, 45 became 15 and 1987 became 7.

The change in deviance through the inclusion of the parameters in Model 1 is 298.9 on 13 degrees of freedom $(\mathrm{p}<0.0001)$.

The change in deviance through the inclusion of the parameters in Model 2 is 342.8 on 17 degrees of freedom $(p<0.0001)$.

Source: 1991/2 General Household Survey (Authors’ analysis). 